\title{
Flow boiling in vertical narrow microchannels of different surface wettability characteristics
}

\author{
Kan Zhou ${ }^{1}$, Carolyn Coyle 2 , Junye $\mathrm{Li}^{1,3}$, Jacopo Buongiorno ${ }^{2 *}$, Wei $\mathrm{Li}^{1 * *}$
}

\begin{abstract}
:
An experimental investigation of saturated flow boiling in a high-aspect-ratio, one-sided heating rectangular microchannel was conducted with deionized water as the working fluid. The bare silicon wafer bottom surface of the microchannel was hydrophilic with a contact angle of $65^{\circ} \pm 3^{\circ}$, compared with the super-hydrophilic surface deposited by a thin film of 100-nm-thickness silicon dioxide through PECVD with a contact angle less than $5^{\circ}$. In experimental runs the mass fluxes were in the range of $120 \mathrm{~kg} / \mathrm{m}^{2} \mathrm{~s}$ $360 \mathrm{~kg} / \mathrm{m}^{2} \mathrm{~s}$, the wall heat fluxes were spanned from $4 \mathrm{~W} / \mathrm{cm}^{2}$ to $20 \mathrm{~W} / \mathrm{cm}^{2}$ and the inlet vapor qualities were varied from 0.03 to 0.1 . Parametric study and flow visualization on pressure drop, local heat transfer coefficient, and flow pattern for surfaces of different surface wettability characteristics were carried out. Measured total pressure drops in single phase and two phase flow experiments agreed well with predicted values. The experimental data points were almost all located in the annular flow regime, and the local heat transfer coefficients approached a constant value and then increased towards the exit along the flow direction. According to flow visualization, the local dryout phenomenon occurred on the untreated hydrophilic surface at high heat fluxes for low mass fluxes, accompanied with deteriorative heat transfer performance, while it was not observed on the super-hydrophilic surface at the identical condition. Meanwhile severe heat transfer deterioration was obtained on the hydrophilic surface with increased inlet vapor quality, while the heat transfer coefficient of the super-hydrophilic surface was relatively constant which outperformed the untreated silicon wafer surface without increased pressure drop penalty.
\end{abstract}

KEYWORDS: Microchannel, Saturated flow boiling, Pressure drop, Flow pattern, Local heat transfer coefficient

\begin{tabular}{|c|c|}
\hline \multicolumn{2}{|c|}{ Nomenclature } \\
\hline$A$ & Cross-section area, $\left[\mathrm{m}^{2}\right]$ \\
\hline$C$ & Martinelli-Chisholm constant, [-] \\
\hline$D_{\mathrm{h}}$ & Hydraulic diameter, $[\mathrm{m}]$ \\
\hline$G$ & Mass flux, $\left[\mathrm{kg} / \mathrm{m}^{2} \mathrm{~s}\right]$ \\
\hline$h$ & $\begin{array}{l}\text { Heat transfer coefficient, }\left[\mathrm{W} / \mathrm{m}^{2} \mathrm{~K}\right] \\
\text { Specific enthalpy, }[\mathrm{J} / \mathrm{kg}]\end{array}$ \\
\hline$I$ & Current, $[\mathrm{A}]$ \\
\hline$J$ & Superficial velocity, $[\mathrm{m} / \mathrm{s}]$ \\
\hline$L$ & Length, $[\mathrm{m}]$ \\
\hline$q$ & Heat flux, $\left[\mathrm{W} / \mathrm{m}^{2}\right]$ \\
\hline
\end{tabular}




$\begin{array}{ll}Q & \text { Heat, [W] } \\ T & \left.\text { Temperature, [K or }{ }^{\circ} \mathrm{C}\right] \\ U & \text { Voltage, }[\mathrm{V}] \\ W & \text { Width, [m] } \\ x & \text { Vapor quality, [-] } \\ X & \text { Lockhart-Martinelli parameter, [-] } \\ z & \text { Axial coordinate, }[\mathrm{m}]\end{array}$

Greek symbols

$\begin{array}{ll}\triangle P & \text { Pressure drop between inlet and outlet, }[\mathrm{Pa}] \\ & \text { Density of fluid, }\left[\mathrm{kg} / \mathrm{m}^{3}\right] \\ & \text { Surface tension, }[\mathrm{N} / \mathrm{m}] \\ & \text { Void fraction, }[-] \\ & \text { Inclination angle, }\left[^{\circ}\right] \\ & \text { Contact angle, }\left[^{\circ}\right] \\ & \text { Two-phase frictional multiplier based on } \\ & \text { local liquid flow rate }\end{array}$

Subscripts

$\begin{array}{cl}\text { eff } & \text { Effective } \\ l & \text { Liquid } \\ i & \text { Local } \\ \text { in } & \text { Inlet } \\ \text { mea } & \text { Measurement } \\ \text { out } & \text { Outlet } \\ \text { sat } & \text { Saturation } \\ \text { tot } & \text { Total } \\ t p & \text { Two phase } \\ v & \text { Vapor } \\ w & \text { Wall } \\ z & \text { Axial coordinate }\end{array}$

\section{INTRODUCTION}

Many industrial applications such as high-power electronic devices, nuclear and conventional power plants, refrigeration and air conditioning systems, aerospace station, to mention a few, rely on boiling to transfer large heat fluxes across system boundaries [1]. Compared against single-phase fluid loops, better heat transfer performance can be attained at lower mass flow rates for heat sinks utilizing flow boiling at cost of increased pressure drop, accompanied with a more uniform distribution of surface temperature due to the constant fluid temperature in the two-phase regime [2].

Ribatski et al. [3] and Qu et al. [4] stated that microchannel heat sinks utilizing flow boiling outperforms conventional macroscale ones for the combination of higher surface area per volume and much higher heat transfer coefficients as well as minimal mass velocity. In recent years, an increasing number of micro-scale heat exchange devices are based on heat transfer through the phase change of liquid coolants in microchannels combined with various geometries and orientations [5]. Microchannel flow boiling heat sinks which combine the attributes of high surface area to volume ratio, enhanced convective heat transfer performance and small coolant inventory constitute an innovative solution for cooling schemes of the high heat-dissipation requirement from a small area in sophisticated devices [6], which have been involved in a wide range of industrial applications such as the microfluidic system [7] and microelectronic technology [8].

Kandlikar [9] stated the divergences between heat transfer mechanisms of microchannels and 
classic macroscale in the two phase flow regime. The bubbles generated from boiling incipience of the liquid coolant on the superheated surface are confined between the surrounding walls with decreased channel dimensions, thus giving distinctly different regularities of the flow patterns, heat transfer, pressure drop, instability and critical heat flux from those in the macroscale channels. Li and $\mathrm{Wu}$ studied the heat transfer characteristics of evaporation in micro/mini-channels and presented a criterion, $B o^{*} \operatorname{Re}_{l}{ }^{0.5}=200$ and $B o=4$ as transitions of flow boiling between the microscale and macroscale [10]. Based on the criterion, correlations for pressure drop, heat transfer, and critical heat flux in the microscale were developed [11]. Thome et al. [12, 13] investigated the influence of confinement number on the two-phase flow regimes and liquid film distribution in a single circular horizontal channel. They proposed a new macro-microscale transition flow pattern map, which postulated the lower threshold of macroscale flow is Co $=0.3-0.4$ while the upper threshold of symmetric microscale flow is $\mathrm{Co} \geq 1$ while the transition (or mesoscale) region locates in-between [12]. Furthermore, a new CHF (critical heat flux) correlation was also developed which accounted for the macro-microscale confinement and the viscous interfacial shear effects on CHF [13]. At the same time attention has been paid to study the influence of micro/nano-scale fabricated surface on heat transfer enhancement. The Buongiorno group at MIT investigated the separate effects of surface characteristics such as hydrophilicity, porosity and roughness on CHF, and found that large CHF enhancement can be obtained with textured surfaces that produce strong wicking of liquid to the surface [14]. They also observed that CHF maxima can be obtained depending on the geometric characteristics of the surface structures, such as thickness of the porous layer and size of the pores which determined the competition between conduction heat transfer within the porous layer, as well as capillary wicking, viscous pressure drop and evaporation [15], or spacing and size of the micro-pillars which influenced characteristic dry spot heating and rewetting timescales during boiling crisis [16]. Mechanistic models were also developed to explain those CHF maxima capturing the geometrical parameters while provided guidelines for further optima $[15,16]$.

While in macroscale channels inertia and buoyancy forces have determined effect on the flow structures and hydraulic and thermal transport process, the surface tension and surface characteristic parameters such as surface porosity, roughness, and wettability are just of the same importance in the microchannel. In the meantime micro/nano-scale surface modification techniques which structure the heat transfer surface with higher surface area to volume ratio and nucleation sites, can effectively change all the surface characteristic parameters including surface roughness, wettability and porosity simultaneously. Design and optimization of the microchannel heat sinks and surface modification methods have been emerging in recent years, both of which intend to pursue low boiling incipience superheat, high heat transfer coefficient under practically applied heat fluxes, and high critical heat flux $[14-16,17]$. Thus the combination of surface micro/nano-structures and microchannel heat sinks may promise a much better heat transfer performance at cost of minimal pressure drop increment compared to untreated surfaces without apparent changes in the surface topography.

Most experimental investigations presented in the literature so far, concern micro/nano-scale structured surfaces focusing on microscale structures such as micro-roughness, micro-cavities and micro-porosity for heat transfer enhancement [18-21]. However, the underlying physical mechanisms as for how micro/nano-scale structures enhance HTC (heat transfer efficient) and CHF are still not well understood. Meanwhile, the effect of surface wettability on the aforementioned performance of the various modified boiling surfaces has been studied in part of prior work [17, 22-28].

Generally speaking, a latish ONB (onset of nucleate boiling) and suppressed heat transfer performance at low heat fluxes coupled with high CHF values can be attained on homogeneously hydrophilic-wettability boiling surfaces [17], which are featured by contact angle $<90^{\circ}$. On the contrary, earlier establishment of boiling incipience results in higher heat transfer coefficients at low heat fluxes for uniformly hydrophobic-wettability surfaces with a contact angle $>90^{\circ}$, while pronounced bubble coalescence accompanied with formation of a blocking vapor film surrounding the superheated surface can cause lower CHF values.

In the experimental work of Rioboo et al. [22], the heated surfaces were partially chemically grafted with alkylsilane SAMs (self-assembled monolayers) by micro-contact printing, forming SAM patterned hydrophobic zone against the rest hydrophilic part. It was observed that the density of nanobubbles nucleated on the patterned hydrophobic zone was higher than that on the hydrophilic section, resulting in enhanced liquid-vapor phase change on the SAM patterned zone. Their results verified the surface wettability effect on the nano-bubble density and local heat flux distribution of the heated surface as a function of the chemical heterogeneities and wettability contrast. In a later experimental study carried out by Choi et al. [23], water flow boiling in rectangular hydrophilic and hydrophobic microchannels were investigated to consider the surface wettability which was found to be a critical parameter on the two-phase flow pattern and hydraulic and thermal transport process. The bare hydrophilic microchannel made of photosensitive glass was chemically treated to become hydrophobic in which flow boiling heat transfer and pressure drop measurements were carried out. It was found that heat transfer coefficient of the hydrophobic surface was higher than that of the hydrophilic surface at 
cost of greater pressure drop, which was highly related with increased nucleation site density, liquid film formation and unstable motions of bubbles.

Simultaneously Liu et al. fabricated three heat transfer surfaces of distinct wettability in microchannels with identical geometries of $105100030000 \mu \mathrm{m}^{3}$ to evaluate the flow boiling hydraulic and thermal performance [24]. The plain silicon wafer surface machined through the plasma etching process was hydrophilic with a contact angle of $36^{\circ}$, compared with hydrophobic surface coated by a thin film of low surface energy material with a contact angle of $103^{\circ}$, and super-hydrophilic surface after growth of nanowire arrays. It was observed that on the hydrophilic surface cyclic flow process happened much associated with the nucleation, growth and coalescence of bubbles. While for the case of the hydrophobic surface, it led to severe superheat of the liquid phase and sharp growth of nucleated bubbles after boiling incipience. As for the super-hydrophilic surface featured with nanowire arrays, generation of a great number of bubbles can be found which may be caused by many defects formed between the nano-spaced rings on the nanowire fabricated surface.

Concerning convective boiling of various working fluids in structured microchannels with different surface wettability, Hsieh et al. conducted a comprehensive experimental investigation for subcooled flow boiling in a microchannel heat sink of 75 parallel $100 \times 200 \mu \mathrm{m}^{2}$ channels $[25,26]$. The side walls were decorated with $50 \times 100 \mu \mathrm{m}^{2}$ micro cavities with angles of $60^{\circ}, 90^{\circ}$ and $120^{\circ}$, while the bottom wall was coated with or without $2-\mu \mathrm{m}$-thickness diamond film to account for the hydrophilic/ hydrophobic surface effect. Flow morphologies, onset of nucleate boiling, convective heat transfer coefficients and critical heat fluxes were obtained with de-ionized water, de-ionized water nano-fluid with 1 vol. \% MCNT additive and FC-72 dielectric coolant. Their results indicated that the hydrophilic surface presented a higher CHF than the hydrophobic counterpart [25], as could be expected. Meanwhile the combination of the sputtered ultrathin film associated with the nano-fluid formed a more hydrophilic contact interface [26]. Its heat transfer performance was augmented significantly, which benefitted from the promotion of bubble nucleation and reduction of the initial superheat for boiling incipience.

Bubble dynamics studies carried out by Ahmadi and Okawa to investigate hydrophilic versus hydrophobic surface in a vertical upward mini-channel for subcooled flow boiling revealed contrasting mechanisms of the bubble growth and departure process [27]. It was concluded that in the ONB regime, generated bubbles on the hydrophilic surface lifted off into the subcooled liquid at atmospheric pressure or slid on the heated surface at increased pressures after departure from the nucleation sites. While in the hydrophobic channel, nucleated bubbles attached to the nucleation sites accompanied with growth and shrinkage on site. The triggering mechanisms for OSV (onset of significant void) on the hydrophilic surface were derived from the reattachment of lift-off bubbles at atmospheric pressure and wake effect of preceding sliding bubbles at elevated pressure. While for the hydrophobic counterpart departure of bubbles from the nucleation sites was a necessary condition for OSV.

As few researches were attempted to explore the effect of heterogeneous walls of hybrid surface wettability on the flow dynamics in micro/mini channels, Cho et al. conducted an experimental investigation for heterogeneous surface properties in the microchannel [28]. The heterogeneous surfaces of the rectangular microchannel was featured by three hydrophilic polycarbonate walls coupled with the bottom wall hydrophobic which was fabricated by either smooth carbon paper or rough polytetrafluoroethylene sheet, compared against a homogeneous smooth hydrophilic microchannel. Through top and cross-sectional views it was observed that liquid phase was preferentially presented in the corners away from the hydrophobic surface causing distinct two-phase flow regime and pressure drop. Empirical pressure drop correlation predictions, based on the LockhartMartinelli parameter or two-fluid approach, along with model parameter optimization utilizing their experimental data were obtained, showing acceptable agreement with experimental measurements for the various modified surfaces, respectively.

As can been seen from the foregoing researches, the influence of surface property with various wettability on flow boiling is complicated and distinct. The above literature review provides valuable insight into the flow boiling heat transfer in the micro-scale channel with different surface wettability, and the associated bubble dynamics has received some attention from the limited experimental work available. But a more detailed understanding of the underlying conjugate hydraulic and thermal transport mechanism is required to better evaluate the heat transfer and pressure drop characteristics of distinct hydrophilic and hydrophobic surfaces, which is the major objective of the present study. In this study experimental measurements and flow visualizations were carried out for the local heat transfer coefficient, pressure drop and flow patterns of saturated flow boiling in a narrow microchannel utilizing deionized water as the working fluid on hydrophilic and super-hydrophilic surfaces, respectively. The experimental mass fluxes were in the range of $120 \mathrm{~kg} / \mathrm{m}^{2} \mathrm{~s}-360 \mathrm{~kg} / \mathrm{m}^{2} \mathrm{~s}$, the wall heat fluxes varied from $4 \mathrm{~W} / \mathrm{cm}^{2}$ to $20 \mathrm{~W} / \mathrm{cm}^{2}$ and the inlet vapor quality of the test section ranged from 0.03 to 0.1 . Existing empirical correlations were utilized to confirm the accuracy of single and two phase pressure drop measurements.

\section{EXPERIMENTAL SETUP AND PROCEDURES}




\subsection{Experimental Setup and Test Module}

The flow boiling experimental setup is a closed loop as schematically shown in Fig. 1. During the experimental study, deionized water is used as the working fluid. Deionized water is degassed in the pressurized storage tank before experimental runs and flows through the oil-free magnetic gear micropump, filter, Coriolis mass flow meter, high temperature water bath (preheater 1), cartridge preheater (preheater 2) successively and then the test module before returning to the storage tank.

In the first preheater the working fluid is heated up in a plate-type heat exchanger by circulated high temperature water from the thermostatic water bath. A second preheater is located upstream of the test module and is used to heat the deionized water to the required saturation temperature and inlet quality for the saturated flow boiling test runs. The preheater is a stainless steel cartridge heater, the power of which is supplied by a manually controlled voltage converter. A needle valve is installed downstream of the test module for the purpose of avoiding the propagation of hydraulic and thermal instabilities from the boiling fluid to the main circuit. Downstream the needle valve overheated deionized water flows through another plate-type heat exchanger to be condensed and then back to the storage tank. The water storage tank is used to boil deionized water for degassing and regulate the saturation pressure simultaneously.

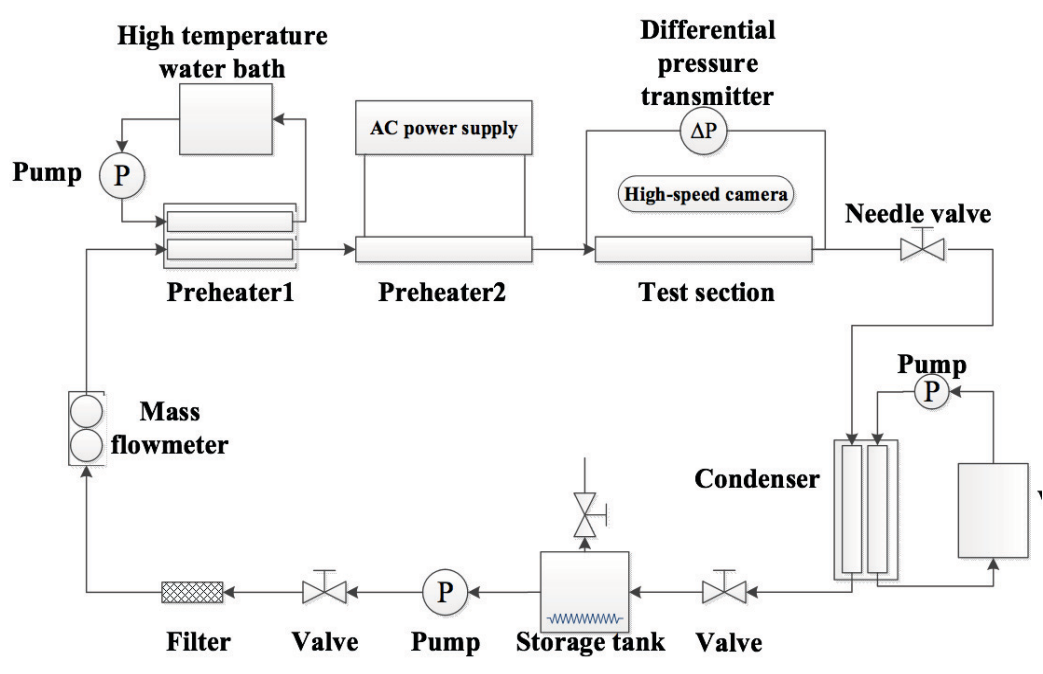

Fig. 1 Schematic of setup for flow boiling in micro/mini-channels

The narrow microchannel test module is composed of the cover plate and house plate made of PSU (polysulfone) which are schematically shown in Fig. 2 and Fig. 3. As shown in Fig. 2a, a microgroove of $80 \mathrm{~mm}$ length and $0.52 \times 5.01 \mathrm{~mm}^{2}$ (depth $\times$ width) cross sectional area is machined into the downside of the cover plate, allowing for high-speed flow visualization meanwhile constructing the flow channel after bolting together the cover and house plate. The inlet and outlet plenums, temperature and pressure measurement taps and a rectangular opening of $15 \times 30 \times 8 \mathrm{~mm}^{3}$ (width $\times$ length $\times$ depth) are machined in the house plate as shown in Fig. $2 b$. Inside the rectangular opening the PEEK (polyether-ether-ketone) supporter which contains the cooper temperature sensors and heating electrodes is installed upon the silicone rubber gasket, under the test silicon wafer and coil heating ceramic chip successively (Fig. 3c). The aforementioned test components are held together by bolt fasteners and sealed with O-rings, permitting convenient assembly and disassembly of the various components for different experimental designs.

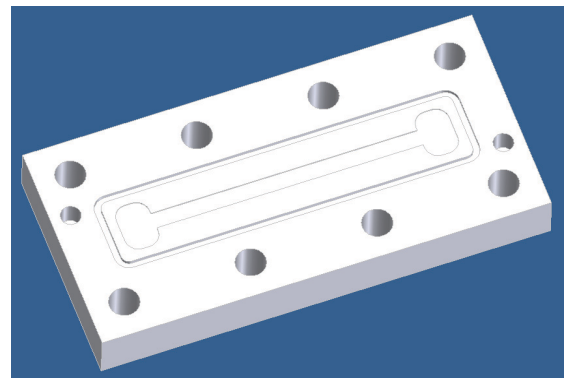

(a) Cover plate

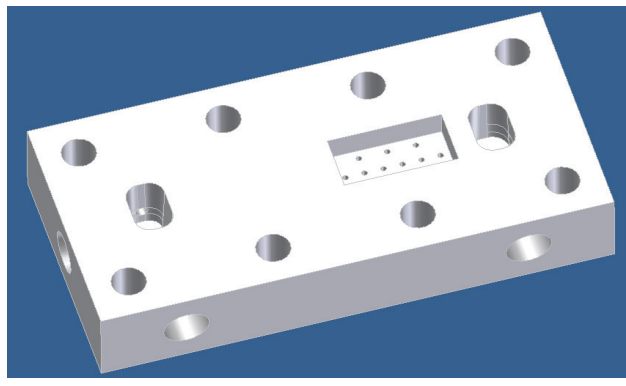

(b) House plate 


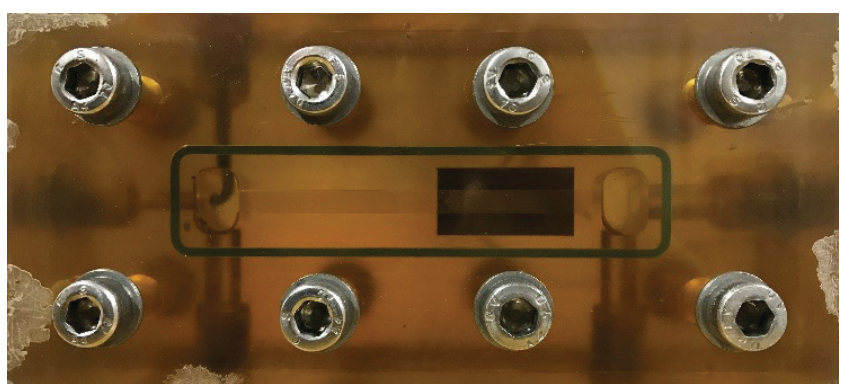

(c) Front view

Fig. 2 Cover and house plates for the micro/mini-channel test module

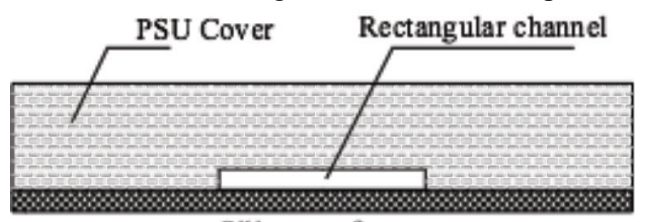

Silicon wafer

(a) Rectangular cross section of the flow channel

(b) Coil heating ceramic chip

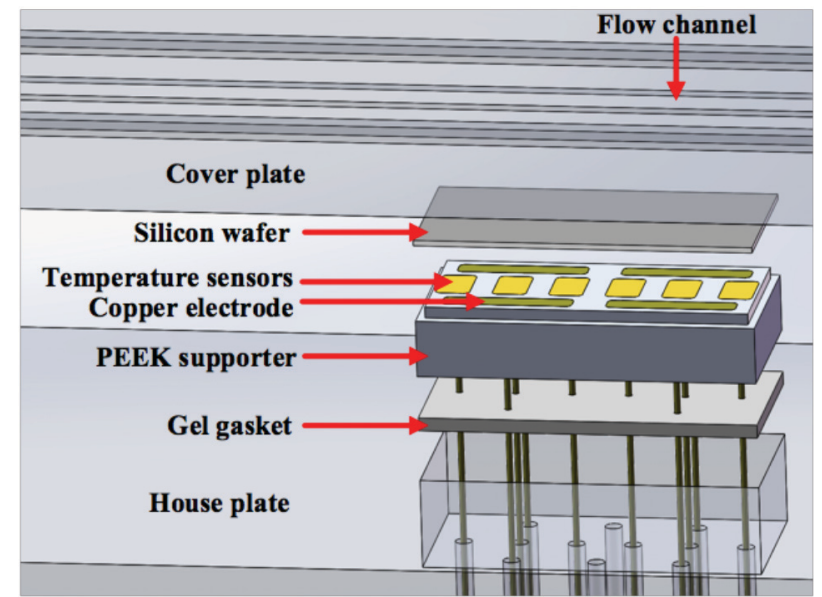

(c) Test section assembly

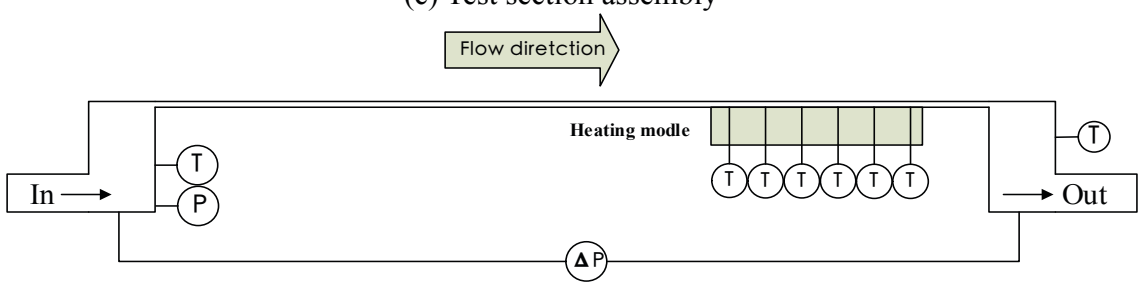

(d) Schematic of the measure points inside the test module

Fig. 3 Schematic of the micro/mini-channel test section

The inlet pressure of the test module is measured by the pressure transmitter and the pressure drop along the test module is measured using the differential pressure transmitter. Fluid bulk temperatures at the inlet plenum and outlet plenum of the test module are measured by the $0.3 \mathrm{~mm}$ T-type thermocouple and $1 \mathrm{~mm}$ outer-diameter K-type sheathed thermocouple, respectively. The bottom surface temperature of the test section is measured utilizing custom miniature copper temperature sensors coupled with $0.254 \mathrm{~mm}$ T-type thermocouples which are embedded within the PEEK supporter at six axial locations, namely $2.5,7.5,12.5,17.5,22.5$ and $27.5 \mathrm{~mm}$ from the front edge of the silicon 
wafer along the flow direction while the heated length of the micro-channel is $30 \mathrm{~mm}$, as shown in Fig. 3(d). All the thermocouples used are calibrated with temperature measurement uncertainty of $\pm 0.1^{\circ} \mathrm{C}$. The silicon wafer is heated by supplying direct current to the ceramic chip through regulating the direct power supply manually. Meanwhile thermal insulation of the experimental setup is provided by covering connecting pipes and heat exchange devices with elastomeric foam.

\subsection{Surface Treatment and Test Procedure}

The bare silicon wafer surface was naturally hydrophilic. The super-hydrophilic surface was prepared by placing the entire silicon wafer into the PECVD (plasma enhanced chemical vapor deposition) chamber. The fabrication procedures were as follows: $\mathrm{N}_{2} \mathrm{O}$ was injected and reacted with silane in the vacuumed chamber at ambient temperature, forming nanoscale silicon dioxide particles which were then deposited on the smooth silicon wafer.

The originally hydrophilic surface would exhibit super-hydrophilicity or slightly higher hydrophilicity characteristics when silicon dioxide particles were deposited on the silicon wafer substrate surface with deposition thickness of $100 \mathrm{~nm}$ or $1000 \mathrm{~nm}$, respectively. The sessile drop method with deionized water was utilized to measure the static contact angle of each surface. The contact angles were $65^{\circ} \pm 3^{\circ}, 50^{\circ} \pm 3^{\circ}$ and less than $5^{\circ}$ for the bare silicon wafer, $1000 \mathrm{~nm}$-thickness and $100 \mathrm{~nm}$-thickness silicon dioxide deposited surface, respectively (Fig. 4). To highlight the surface wettability effect, the untreated silicon wafer and nanoscale modified super-hydrophilic surface were utilized as the test objects in the saturated boiling experiments of the present study.

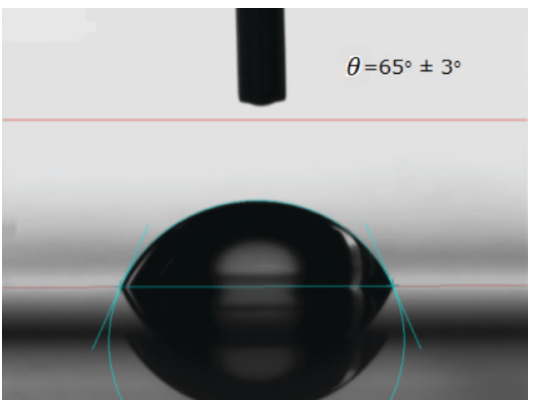

(a)

Untreated silicon wafer

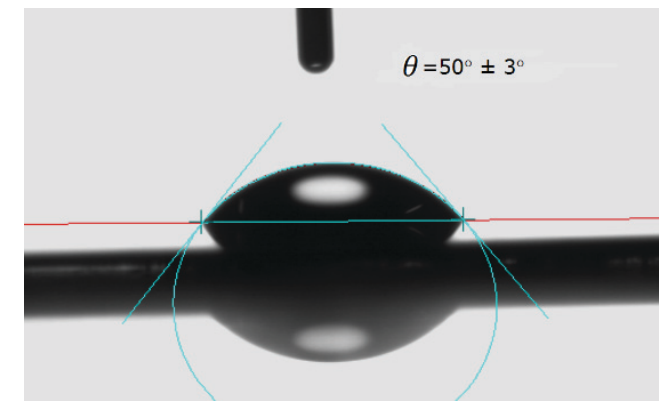

(b)
Silicon wafer deposited by $1000 \mathrm{~nm}$ silicon dioxide deposition layer

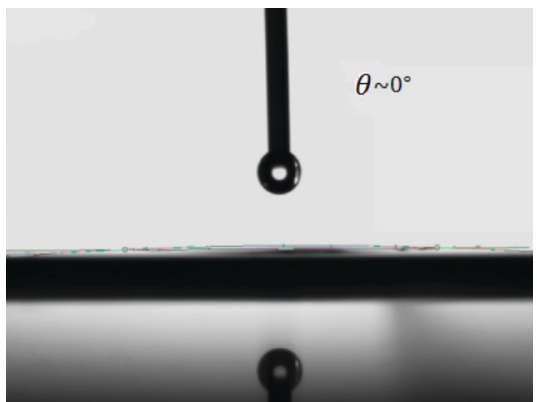

(c) Silicon wafer deposited by $100 \mathrm{~nm}$ silicon dioxide deposition layer

Fig. 4 Measured static contact angles for different surfaces

Experimental measurements and flow visualization were carried out for the local heat transfer coefficient, pressure drop and flow pattern of saturated flow boiling in the microchannel to account for the effect of surface wettability. The measured data such as temperatures at various locations, pressure, pressure drop, mass flux, supplied currents and voltages in the experimental system were recorded by the Agilent 34970A data acquisition instrument with two 20-channel 34901 multiplexers, whose sampling frequency was at an interval of $5 \mathrm{~s}$. The microscope and Phantom high-speed digital video camera coupled with a light system were used to visualize and record the flow patterns for analysis. During the experiments, the mass fluxes were in the range of $120 \mathrm{~kg} / \mathrm{m}^{2} \mathrm{~s}-360 \mathrm{~kg} / \mathrm{m}^{2} \mathrm{~s}$, the wall heat fluxes were varied from $4 \mathrm{~W} / \mathrm{cm}^{2}$ to $20 \mathrm{~W} / \mathrm{cm}^{2}$ and the inlet vapor quality ranged from 0.03 to 0.1 . Experimental results were obtained under the operational conditions as illustrated in Table 1.

Table 1 Test conditions for saturated flow boiling test runs

\begin{tabular}{l|l} 
Test surface & $\begin{array}{l}\text { silicon wafer/100 } \mathrm{nm} \text { silicon dioxide deposited silicon wafer } \\
\text { Working fluid }\end{array}$ \\
deionized water
\end{tabular}

Mass flux

$120,240,360 \mathrm{~kg} / \mathrm{m}^{2} \mathrm{~s}$ 


\begin{tabular}{l|l} 
Heat flux & $4-20 \mathrm{~W} / \mathrm{cm}^{2}$ \\
Inlet vapor quality & $0.03-0.1$ \\
Inlet pressure & $0.3-11.7 \mathrm{kPa}$
\end{tabular}

At the startup of test runs, deionized water in the storage tank was degassed through boiling up for one hour. After degassing, dissolved oxygen (DO) content within the boiled water was measured using a DO sensor (Mettler Toledo InPro 6850i/12/120). The measured DO content was $3.7 \mathrm{ppm}$ at $34{ }^{\circ} \mathrm{C}$. Meanwhile the thermostatic water bath was switched on and regulated to provide the required preheating temperature. Then the system loop was flushed with deionized water over a period of 30$60 \mathrm{~min}$ for maintenance while caution was taken to avoid any non-condensable gas arising in the main circuit. The alternating current supplied to the cartridge heater was manually controlled to attain the desired inlet quality for saturated flow boiling test runs. The power supplied to the ceramic heating chip was incremented in steps, and the test facility was left to reach the steady state for at least 10min before the steady-state instrumental data were recorded. Measured temperature and pressure data used for calculations were the averages of at least twenty continuous readings. The same procedure was repeated for each operational condition until a maximum set-point heating chip power was reached and then the power supplied to the test section was switched off.

\subsection{Data Reduction}

The thermal boundary condition in the bottom of the test section was assumed to be uniform axial heat flux and uniform circumferential wall temperature with the other sides adiabatic. Local temperatures of the silicon wafer surface were calculated through one-dimension heat conduction. The corresponding fluid local saturation temperatures were given by linear interpolation of saturation temperatures at the inlet and outlet plenums as the pressure drop across the flow channel was low.

The effective heat transfer rate to the working fluid can be expressed as:

$$
Q_{\text {eff }}=U \times I
$$

where $U$ and $I$ are the electrical voltage and current supplied to the ceramic heating chip. Heat loss to the environment was found to be less than $3 \%$ for saturated flow boiling experiments which was considered in the experimental certainty of wall heat flux and HTC.

The local heat transfer coefficient is calculated adopting the definition below:

$$
h_{z}=\frac{q}{\left(T_{\mathrm{w}, \mathrm{z}}-T_{\mathrm{sat}, \mathrm{z}}\right)}=\frac{Q_{\mathrm{eff}}}{A_{\mathrm{h}}\left(T_{\mathrm{w}, \mathrm{z}}-T_{\mathrm{sat}, \mathrm{z}}\right)}
$$

where $A_{h}=W \times L$ refers to the heated area of the microchannel and $q$ is the wall heat flux, meanwhile $T_{w, z}$ and $T_{s a t, z}$ are the local temperature of the silicon wafer surface at axial location $z$ and corresponding fluid saturation temperature, respectively.

The local vapor quality is calculated through the energy balance as follows:

$$
\begin{gathered}
h_{0}=x_{0} h_{\mathrm{v}, 0}+\left(1-x_{0}\right) h_{\mathrm{l}, 0} \\
h_{i}=x_{i} h_{\mathrm{v}, \mathrm{i}}+\left(1-x_{i}\right) h_{1, \mathrm{i}}
\end{gathered}
$$

where $x_{0}, x_{i}, h_{0}, h_{i}, h_{l}, h_{v}$ are the inlet vapor quality, local vapor quality, inlet specific enthalpy, local specific enthalpy, corresponding saturated liquid and vapor specific enthalpy, respectively. The fluidic thermal properties involved in the calculations are based on the local or average bulk temperatures of the working fluid.

The pressure measurement taps are machined in the inlet and outlet plenums of the test module, thus the total pressure drop $\Delta P_{\text {mea }}$ measured by the differential pressure transmitter is given by:

$$
\Delta P_{\text {mea }}=\Delta P_{c}+\Delta P_{e}+\Delta P_{f}+\Delta P_{g}+\Delta P_{a}
$$

The contraction pressure drop $\Delta P_{c}$ inside the inlet plenum for two phase flow is calculated through the homogeneous model [29]:

$$
\begin{gathered}
\Delta P_{\mathrm{c}}=\frac{G^{2}}{2 \rho_{\mathrm{l}}}\left[\left(\frac{1}{C_{\mathrm{o}}}-1\right)^{2}+1-\frac{1}{\sigma_{\mathrm{c}}^{2}}\right] \psi_{\mathrm{h}} \\
\psi_{\mathrm{h}}=1+x\left(\rho_{1} / \rho_{\mathrm{v}}-1\right)
\end{gathered}
$$




$$
\begin{gathered}
C_{\mathrm{o}}=\frac{1}{0.639\left(1-1 / \sigma_{\mathrm{c}}\right)^{0.5}+1} \\
\sigma_{\mathrm{c}}=A_{\mathrm{pl}} / A_{\mathrm{ch}}>1
\end{gathered}
$$

where $\mathrm{G}$ refers to the mass flux and and are the density of liquid and vapor phase, respectively. While $A_{c h}$ and $A_{p l}$ are the cross sectional area of the flow channel and mixing plenum, respectively.

The expansion pressure drop $\Delta P_{e}$ for the outlet plenum is given by the separation model [29]:

$$
\begin{gathered}
\Delta P_{\mathrm{e}}=\frac{G^{2}}{\rho_{\mathrm{l}}} \sigma_{\mathrm{e}}\left(\sigma_{\mathrm{e}}-1\right) \psi_{\mathrm{s}} \\
\psi_{\mathrm{s}}=1+\left(\frac{\rho_{1}}{\rho_{\mathrm{v}}}-1\right)\left[0.25 x(1-x)+x^{2}\right] \\
\sigma_{\mathrm{e}}=A_{\mathrm{ch}} / A_{\mathrm{pl}}<1
\end{gathered}
$$

The two phase frictional pressure drop $\Delta P_{f}$ is given according to the Martinelli model [30]:

$$
\begin{gathered}
-\left(\frac{\mathrm{d} p}{\mathrm{~d} z} F\right)=-\left(\frac{\mathrm{d} p}{\mathrm{~d} z} F\right)_{1} \phi_{1}^{2} \\
\phi_{1}^{2}=1+\frac{C}{X}+\frac{1}{X^{2}} \\
X^{2}=\left(\frac{\mathrm{d} p}{\mathrm{~d} z} F\right)_{1} /\left(\frac{\mathrm{d} p}{\mathrm{~d} z} F\right)_{\mathrm{v}}
\end{gathered}
$$

The two phase gravitational pressure drop $\Delta P_{g}$ is calculated by:

$$
\Delta P_{\mathrm{g}}=\int_{0}^{L_{\mathrm{ot}}} \rho_{t p} g \sin \theta \cdot d L
$$

where $L_{\text {tot }}$ is the total length for the flow channel between the inlet and outlet plenums in the test module, and $\theta$ is the inclination angle of the flow channel while the two phase density, where refers to the void fraction.

Meanwhile the acceleration pressure drop $\Delta P_{a}$ is evaluated using the separation model and Rouhani and Axelsson's drift flux model [31]:

$$
\begin{gathered}
\Delta P_{\mathrm{a}}=G^{2}\left\{\left[\frac{(1-x)^{2}}{\rho_{\mathrm{l}}(1-\varepsilon)}+\frac{x^{2}}{\rho_{\mathrm{v}} \varepsilon}\right]_{\text {out }}-\left[\frac{(1-x)^{2}}{\rho_{1}(1-\varepsilon)}+\frac{x^{2}}{\rho_{\mathrm{v}} \varepsilon}\right]_{\text {in }}\right\} \\
\varepsilon=\frac{x}{\rho_{\mathrm{v}}}\left[(1+0.2(1-x))\left(\frac{x}{\rho_{\mathrm{v}}}+\frac{1-x}{\rho_{\mathrm{l}}}\right)+\frac{1.18(1-x)\left[g \sigma\left(\rho_{1}-\rho_{\mathrm{v}}\right)\right]^{2.25}}{G \rho_{l}^{0.5}}\right]^{-1}
\end{gathered}
$$

The measured total pressure drop $\Delta P_{\text {mea }}$ was compared against the calculation values consisted of the contraction and expansion pressure drops at the inlet and outlet plenums, and the frictional, gravitational as well as acceleration pressure drops as above mentioned.

\subsection{Experimental Uncertainty}

The measurement accuracy or associated experimental uncertainties in both the primary and calculated parameters are estimated and listed in Table 2. Experimental uncertainties of calculated parameters are obtained through the single-sample error propagation method [32]. Basically, consider $y$ is the indirect calculated parameter, which can be calculated from several direct measurements and/or parameter $x_{i}$, as represented by

$$
y=f\left(x_{1}, x_{2} \ldots \ldots, x_{n}\right)
$$

then the experimental uncertainty or propagated error $\delta y$ in $y$ as determined by the measurement accuracy or experimental uncertainty in each independent primary parameter $\delta x_{i}$, can be expressed by the following equation as a relative value:

$$
(\delta y / y)=\left[\left(\partial f / \partial x_{1}\right)^{2} \times\left(\delta x_{1} / x_{1}\right)^{2}+\left(\partial f / \partial x_{2}\right)^{2} \times\left(\delta x_{2} / x_{2}\right)^{2}+\ldots \ldots+\left(\partial f / \partial x_{n}\right)^{2} \times\left(\delta x_{n} / x_{n}\right)^{2}\right]^{0.5}
$$

The measurement accuracies in the primary direct measurements, including the temperature, mass flux, absolute pressure and pressure drop, are $\pm 0.1 \mathrm{~K}, \pm 0.3 \%, \pm 3.75 \%$ and $\pm 1.5 \%$ as shown in Table 2 , respectively. Similarly, the experimental uncertainties in calculating the hydraulic diameter $D_{h}$, heat 
flux $q$, vapor quality $x$, and flow boiling heat transfer coefficient $h$ are estimated and listed in Table 2 .

Table 2 Accuracy estimation for primary measurements and dependent quantities

\begin{tabular}{lc}
\hline & Measured parameters \\
\hline Channel height and width, mm & $\pm 0.005 \mathrm{~mm}$ \\
Test section length, $\mathrm{mm}$ & $\pm 0.01 \mathrm{~mm}$ \\
Wall and fluid temperature, $\mathrm{K}$ & $\pm 0.1 \mathrm{~K}$ \\
Inlet pressure, range: $0-100 \mathrm{kPa}$ & $\pm 3.75 \%$ \\
Inlet and outlet differential pressure, $\mathrm{kPa}$ & $\pm 1.5 \%$ \\
Mass flux, range: $0-540 \mathrm{~kg} / \mathrm{m}^{2} \mathrm{~s}$ & $\pm 0.3 \%$ \\
\hline & Calculated parameters \\
\hline Hydraulic diameter $D_{\mathrm{h}, \mathrm{mm}}$ & $\pm 0.08 \mathrm{~mm}$ \\
Heat flux $q, \mathrm{~kW} / \mathrm{m}^{2}$ & $\pm 3.6 \%$ \\
Vapor quality $x$ & \pm 0.003 \\
Heat transfer coefficient $h, \mathrm{~W} / \mathrm{m}^{2} \mathrm{~K}$ & $\pm 6.8 \%$
\end{tabular}

\section{RESULTS AND DISCUSSION}

\subsection{Single and two phase pressure drop}

In order to validate the experimental setup and data analysis process, pressure drop experiments for single phase and two phase flow in the rectangular microchannel were conducted with de-ionized water. To reduce the influence of experimental uncertainties accompanied with laminar flow development at inlet section as well as contraction and expansion pressure drops, an adiabatic flow channel of $150 \mathrm{~mm}$ length was fabricated with identical cross sectional geometry with the test microchannel to measure adiabatic single phase flow pressure drops at first in order to validate the experimental setup.

Single phase flow experiments were carried out at different temperatures with fixed mass flux as the fluid viscosity increases sharply with decreased fluid bulk temperature, resulting in increased frictional pressure drop. As shown in Fig. 5, measured total pressure drops for the single phase flow experiments agreed well with predicted values according to the calculation procedure by White [29], with prediction deviations of $2.9 \%$ and $6.6 \%$ for low and high temperatures, respectively.

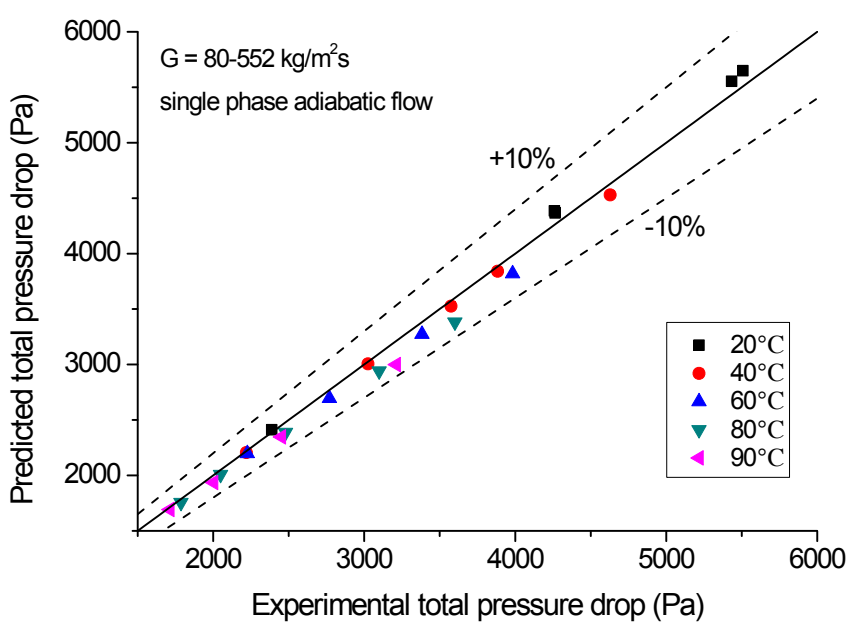

Fig. 5 Measured total pressure drops compared with predicted values (single phase adiabatic flow)

Then the pressure drop measurement for saturated boiling two phase flow in the test microchannel was conducted. The operation conditions of saturated boiling experiments were listed in Table 1. The vapor versus liquid superficial velocity distribution of saturated flow boiling for various inlet vapor qualities and mass fluxes was mapped in Fig. 6(a). There have been a large number of flow regime maps proposed for macro and micro scale channels [33-36] which were also referenced in Fig. 6(a). According to the flow regime maps for upward rectangular channels provided by Hibiki and Mishima [33], Xu et al. [34] and Taitel et al. [35], as well as for horizontal and inclined microchannels put 
forward by Ullmann and Brauner [36], almost all the data points for saturated boiling experiments were located in the annular flow regime. Thus the Martinelli-parameter-based separation model [30] was utilized to calculate the two phase frictional pressure drop. As mentioned above, the empirical void fraction model of Rouhani and Axelsson [31] and frictional pressure drop correlation of English and Kandlikar [30] was utilized to calculate the two phase flow pressure drop (Eq. (18) and (21)).

$$
\phi_{1}^{2}=1+\frac{C\left(1-\mathrm{e}^{-319 D_{\mathrm{h}}}\right)}{X}+\frac{1}{X^{2}}
$$

The measured total saturated boiling pressure drops compared against predicted values were shown in Fig. 6(b), in which the experimental measurements were in good agreement with predictions. Meanwhile it can be indicated that the pressure drop along the flow channel was minimal as concluded above, which verified the data reduction process.

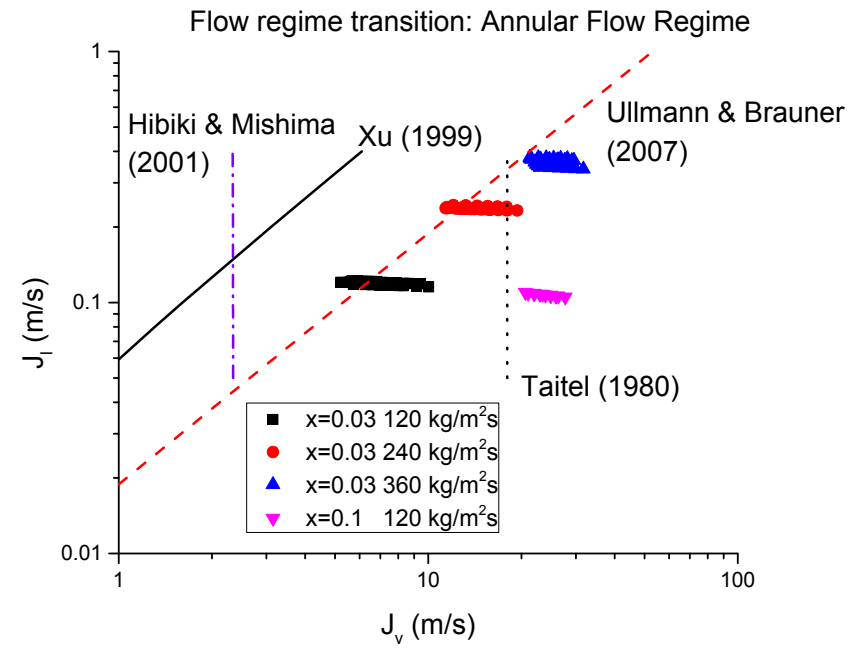

(a) Flow regime map of saturated boiling experiments

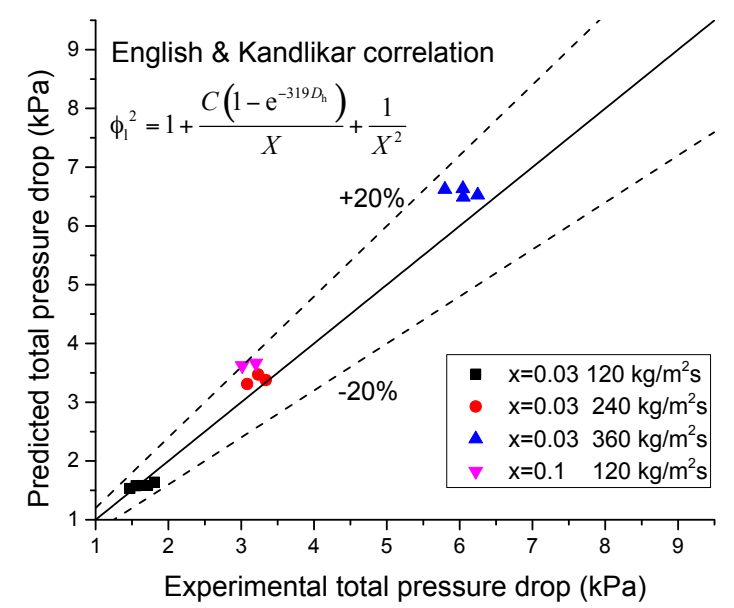

(b) Comparison of experimental total pressure drops with predictions

Fig. 6 Saturated flow boiling experiments for pressure drop measurement

\subsection{Boiling heat transfer of untreated hydrophilic surface}

Fig. 7 showed the local heat transfer coefficients for different mass fluxes with inlet vapor quality of 0.03 , in which repetitive experiment results were also included as shown in Fig. 7(c). The general tendency was that the local heat transfer coefficient attained the maximum at the entrance of the test section, then decreased to the minimum value, and finally began to increase near the exit along the flow direction for all the experimental conditions. The heat loss was greater near the edges of the heated surface, leading to decreased effective heat flux transferred, thus the wall temperature could be less than expected at those locations. Therefore, the data points at the edges of the test section were excluded from the analysis.

However, the HTC still displays minima in the axial direction. This behavior has been observed in other investigations of boiling heat transfer in annular flow [13, 37-39]. Researchers have explained 
this trend as a tradeoff between partial dryout and rewetting phenomenon accompanied with the transition from slug/churn flow to annular flow [13, 37, 39] or flow instability/reversal [13, 37], and thinning of liquid film thickness in the annular flow regime [13, 37, 39]. The issue of flow instability/ reversal can be excluded for the small amplitude of temperature fluctuations measured in our study of steady annular flow. The flow visualization below and the flow regime map in Fig. 6(a) suggest that the HTC minima were present at all the mass fluxes tested with the channel being entirely occupied by annular flow; as well, the flow pattern pictures shown below suggest that local dryout patches were not present at higher mass fluxes. Therefore we also discarded local dryout phenomenon during transition from slug/churn flow as an explanation for the initial decrease of HTC.

The flow conditions in the test section were fully developed annular flow with a developing thermal boundary layer within the liquid film. This caused the initial drop in HTC. However, gradual evaporation and thinning of the liquid film accompanied with augmented vapor velocities caused the local HTC to rise $[13,37,39]$, thus resulting in the minima in the middle of the test section.

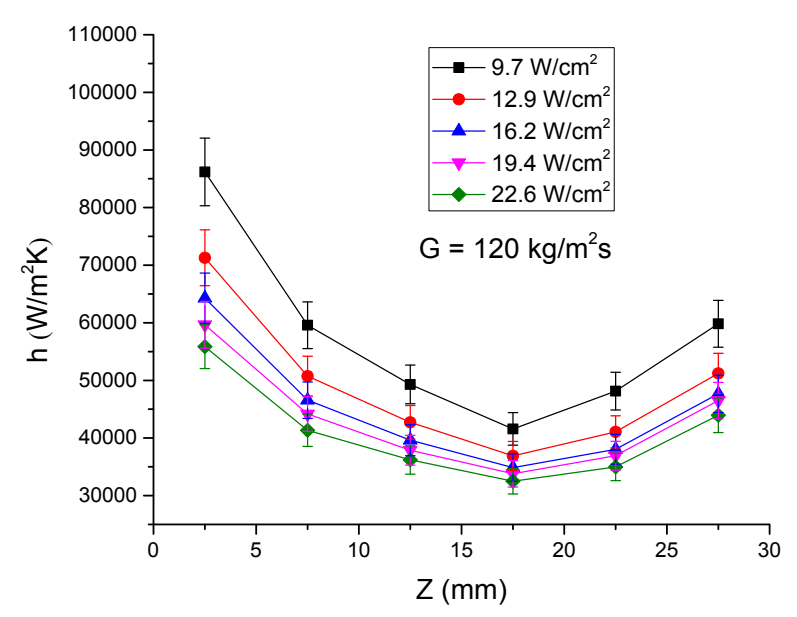

(a) Inlet vapor quality $0.03, \mathrm{G}=120 \mathrm{~kg} / \mathrm{m}^{2} \mathrm{~s}$

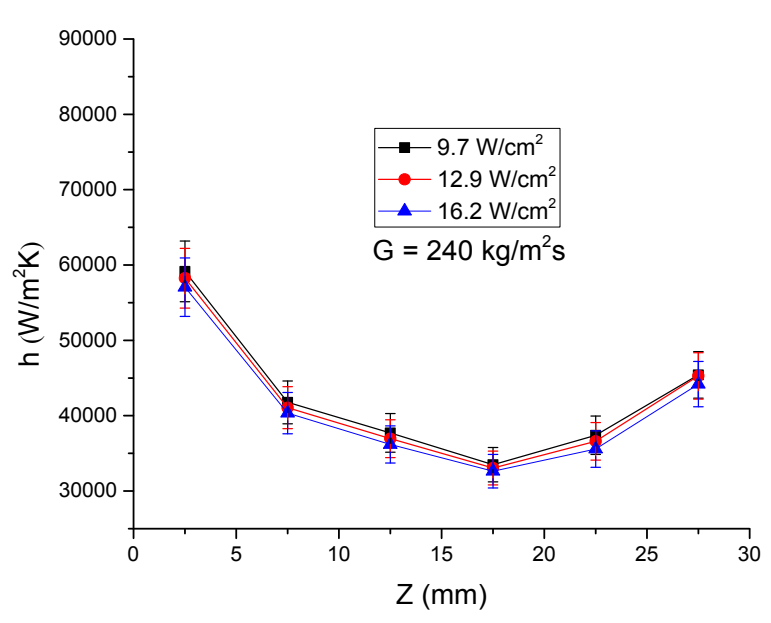

(b) Inlet vapor quality $0.03, \mathrm{G}=240 \mathrm{~kg} / \mathrm{m}^{2} \mathrm{~s}$ 


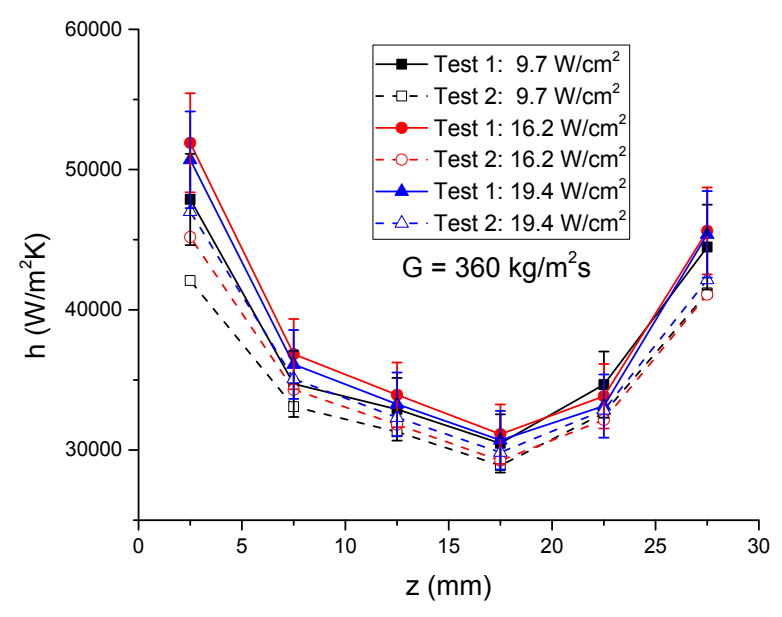

(c) Inlet vapor quality $0.03, \mathrm{G}=360 \mathrm{~kg} / \mathrm{m}^{2} \mathrm{~s}$

Fig. 7 The variation of local heat transfer coefficients with heat flux for different mass fluxes

As shown in Fig. 7(b) and 7(c), the local heat transfer coefficient decreased slightly or did not vary with increased heat fluxes for mass fluxes of $240 \mathrm{~kg} / \mathrm{m}^{2} \mathrm{~s}$ and $360 \mathrm{~kg} / \mathrm{m}^{2} \mathrm{~s}$ respectively, the variation of which lied in the range of experimental uncertainty. When the mass flux shifted to $120 \mathrm{~kg} /$ $\mathrm{m}^{2} \mathrm{~s}$, the local heat transfer coefficient decreased sharply with increments of imposed heat flux, the decrement amplitude of which overpassed the experimental uncertainty of HTC. The conjectured reason for this deteriorative heat transfer performance accompanied with increased heat flux for relatively low mass flux was the local dryout phenomenon [39], which can be explained through flow visualization.

The flow patterns for a mass flux of $120 \mathrm{~kg} / \mathrm{m}^{2} \mathrm{~s}$ and various heat fluxes were visualized by the Phantom high-speed digital video camera at shutter speed of $3000 \mathrm{fps}$. As shown in Fig. 8, partial dryout patches occurred near side walls on the heated silicon wafer surface. The dryout area increased for higher heat fluxes, thus the heat transfer performance deteriorated with increased heat fluxes for the mass flux of $120 \mathrm{~kg} / \mathrm{m}^{2} \mathrm{~s}$.

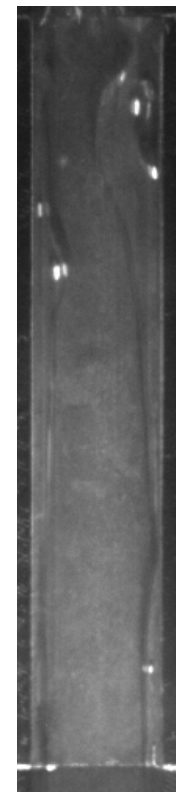

0

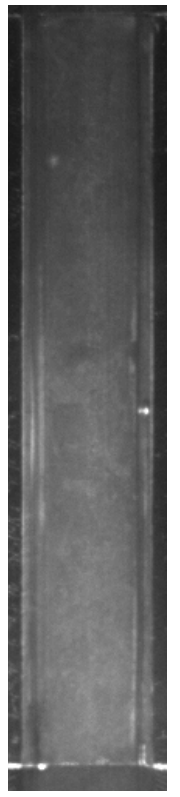

$20 \mathrm{~ms}$

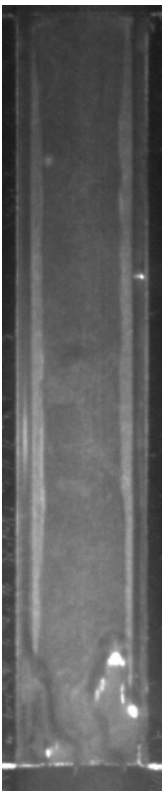

$40 \mathrm{~ms}$

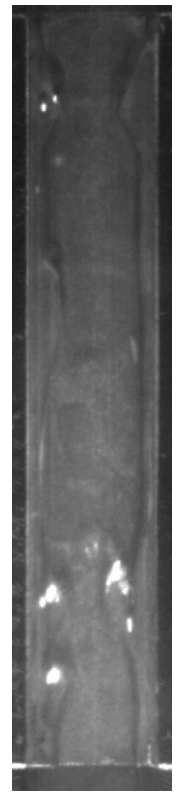

$60 \mathrm{~ms}$

(a) Mass flux $=120 \mathrm{~kg} / \mathrm{m}^{2} \mathrm{~s}$, heat flux $=6.5 \mathrm{~W} / \mathrm{cm}^{2}$ 


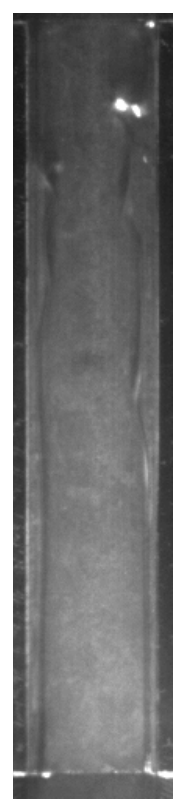

0

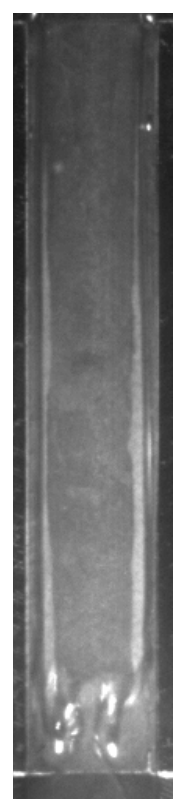

$20 \mathrm{~ms}$

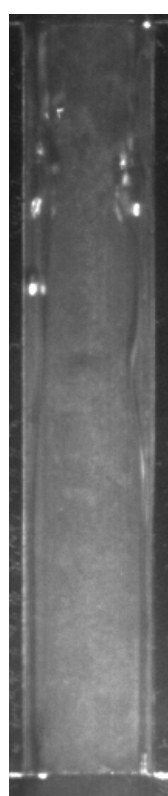

$40 \mathrm{~ms}$

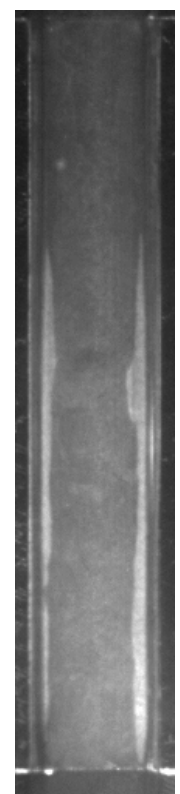

$60 \mathrm{~ms}$

(b) Mass flux $=120 \mathrm{~kg} / \mathrm{m}^{2} \mathrm{~s}$, heat flux $=9.7 \mathrm{~W} / \mathrm{cm}^{2}$

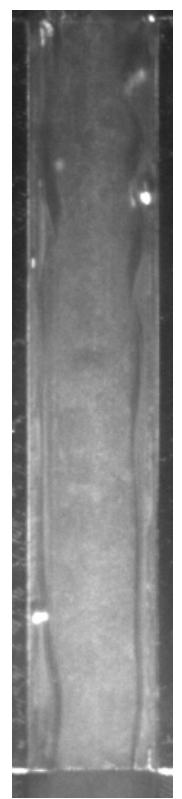

0

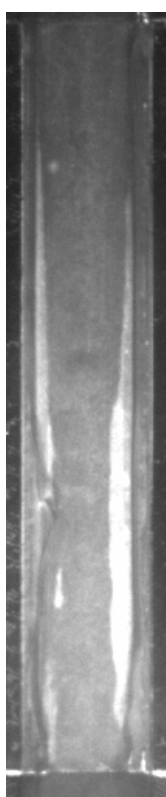

$20 \mathrm{~ms}$

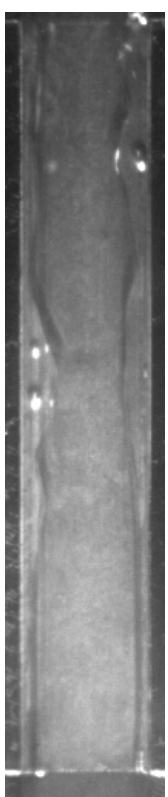

$40 \mathrm{~ms}$

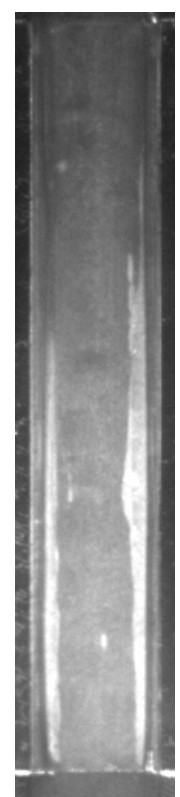

$60 \mathrm{~ms}$

(c) Mass flux $=120 \mathrm{~kg} / \mathrm{m}^{2} \mathrm{~s}$, heat flux $=12.9 \mathrm{~W} / \mathrm{cm}^{2}$

Fig. 8 The variation of flow patterns with time at various heat fluxes for fixed inlet vapor quality of 0.03 and mass flux of $120 \mathrm{~kg} / \mathrm{m}^{2} \mathrm{~s}$ (dryout patches were highlighted by red lines)

\subsection{Boiling heat transfer of super-hydrophilic surface}

Fig. 9 showed the effect of surface wettability on the local heat transfer coefficients between the $100 \mathrm{~nm}$ silicon dioxide deposited super-hydrophilic silicon wafer and untreated bare counterpart with an inlet vapor quality of 0.03 and various imposed heat fluxes for mass fluxes of 120 and $360 \mathrm{~kg} / \mathrm{m}^{2} \mathrm{~s}$. Compared to the untreated hydrophilic surface, the super-hydrophilic wettability effect was negligible in the low vapor quality region for the whole flow velocity range tested. While it was of importance to the local heat transfer coefficient in higher vapor quality region for a lower mass flux of $120 \mathrm{~kg} / \mathrm{m}^{2} \mathrm{~s}$ on the super-hydrophilic surface as shown in Fig. 10. 


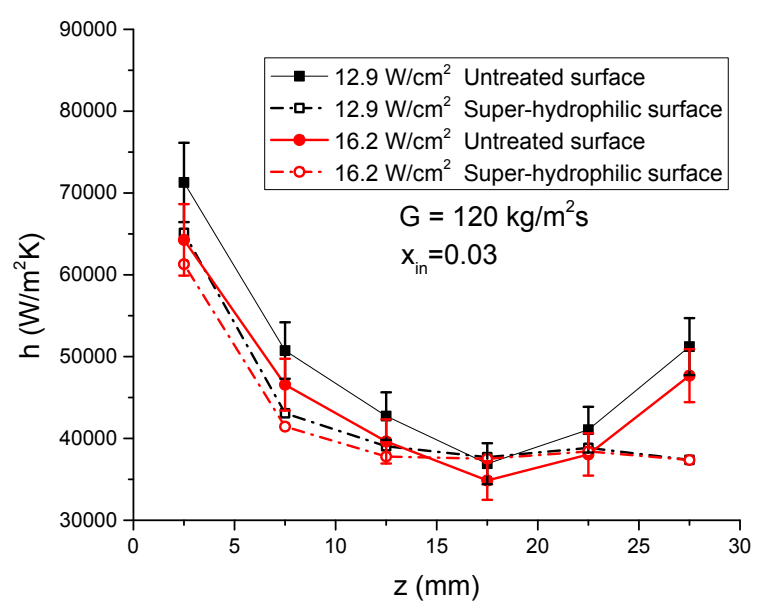

(a)

Inlet vapor quality $=0.03, \mathrm{G}=120 \mathrm{~kg} / \mathrm{m}^{2}$

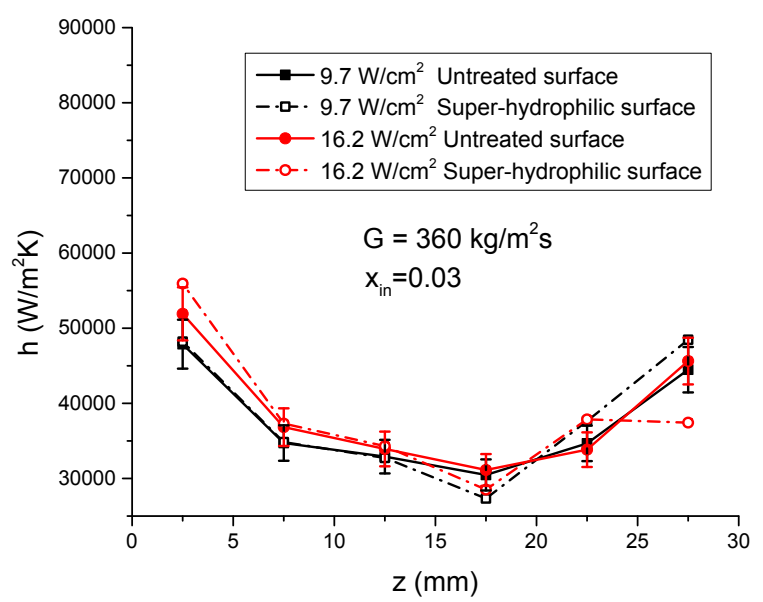

(b)

Inlet vapor quality $=0.03, \mathrm{G}=360 \mathrm{~kg} / \mathrm{m}^{2} \mathrm{~s}$

Fig. 9 The effect of surface wettability on local heat transfer coefficients at low inlet vapor quality

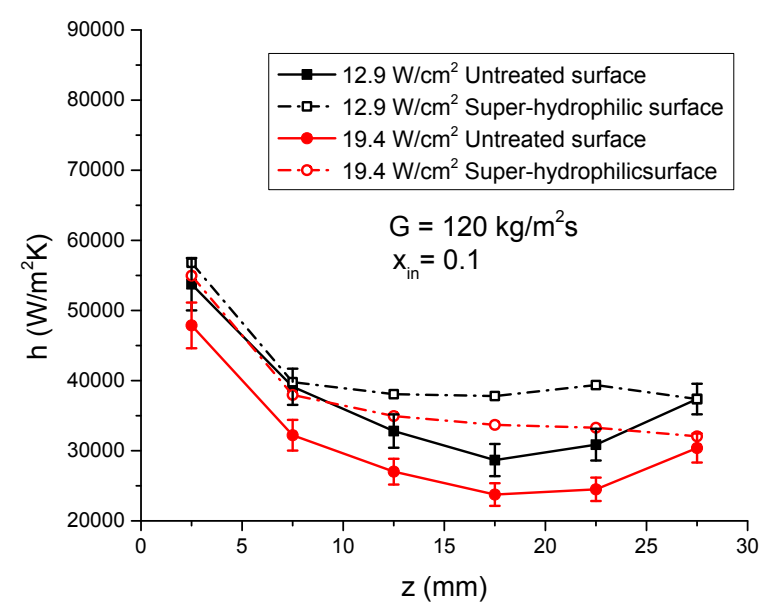

Fig. 10 The effect of surface wettability on local heat transfer coefficients at mass flux of $120 \mathrm{~kg} / \mathrm{m}^{2} \mathrm{~s}$ and inlet vapor quality of 0.1

For low inlet vapor quality, the heat transfer coefficients of super-hydrophilic and hydrophilic surface were basically the same. This was because the local dryout phenomenon did not occur in the low vapor quality region with the heat transfer surface completely covered by the thin liquid film. 
While for the high vapor quality region, the heat transfer coefficients of the super-hydrophilic surface nearly did not vary with increased heat fluxes considering the experimental uncertainty, which outperformed the bare silicon wafer. For the case of super-hydrophilic surface, the abovementioned influences on the local heat transfer coefficient tendency for the untreated surface and super-wettability characteristics both affected the vapor-liquid interface distribution, making the variation trend complicated and slightly different from those of the untreated surface in Fig. 10.

As the surface wettability of the super-hydrophilic silicon wafer was more prominent for high inlet vapor quality regime, the partial dryout patches were not observed compared to the untreated hydrophilic surface, as can be verified by the flow visualization.

The flow patterns for a mass flux of $120 \mathrm{~kg} / \mathrm{m}^{2} \mathrm{~s}$ and inlet vapor qualities of 0.1 and 0.03 on the super-hydrophilic surface were visualized by the high-speed video camera at shutter speed of $3000 \mathrm{fps}$ as shown in Fig. 11(a) and Fig. 11(b), respectively. Compared Fig. 11(a) with Fig. 8(c), it can be observed that the local dryout area was minimal on the super-hydrophilic surface, accompanied by a nearly-constant heat transfer coefficient with increased inlet vapor quality. The super-hydrophilic wettability of the $100 \mathrm{~nm}$ silicon dioxide deposited silicon wafer caused more uniform and continuous distribution of the thin liquid film on the heated surface, which delayed the occurrence of local dryout. Meanwhile it was indicated in Fig. 11(b) that the local dryout area on the super-hydrophilic surface for inlet vapor quality of 0.03 was also much less than that of the untreated hydrophilic surface, but the corresponding local heat transfer coefficients were not augmented and even decreased slightly as shown in Fig. 9(a). This could be caused by the thicker liquid film surrounding the center vapor core on the super-hydrophilic surface, which resulted in increased conduction resistance for the liquid film.

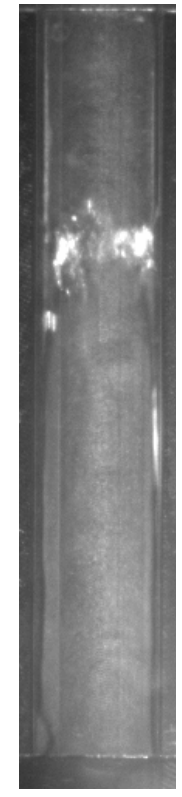

0

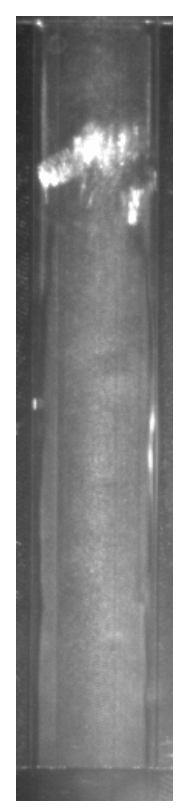

$20 \mathrm{~ms}$

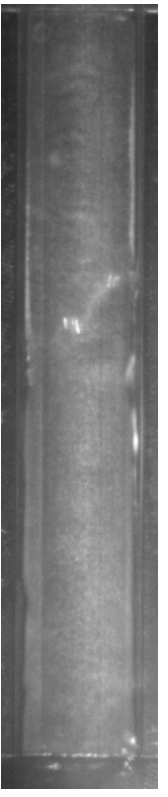

$40 \mathrm{~ms}$

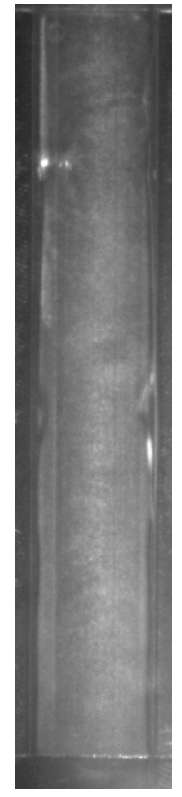

$60 \mathrm{~ms}$

(a) Inlet vapor quality $=0.1$, mass flux $=120 \mathrm{~kg} / \mathrm{m}^{2} \mathrm{~s}$ and heat flux $=12.9 \mathrm{~W} / \mathrm{cm}^{2}$ 


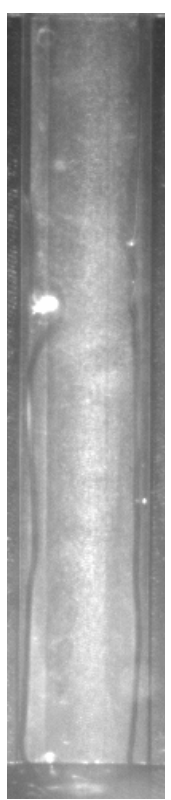

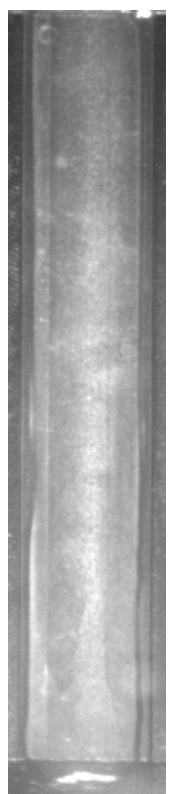

$20 \mathrm{~ms}$

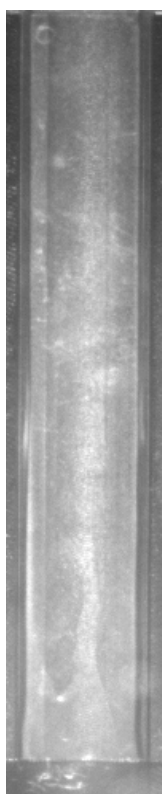

$40 \mathrm{~ms}$

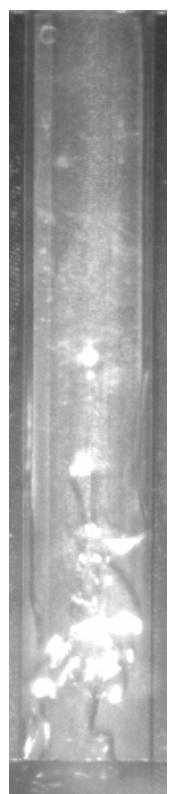

$60 \mathrm{~ms}$

(b) Inlet vapor quality $=0.03$, mass flux $=120 \mathrm{~kg} / \mathrm{m}^{2} \mathrm{~s}$ and heat flux $=12.9 \mathrm{~W} / \mathrm{cm}^{2}$

Fig. 11 The variation of flow patterns with time on the super-hydrophilic surface

As for the pressure drop comparison between the super-hydrophilic surface and untreated hydrophilic counterpart, the measured experimental total pressure drops with inlet vapor quality of 0.03 for saturated boiling experiments across the test module were pictured in Fig. 12. It can be indicated in the figure that measured total pressure drops did not increase significantly in spite of the deposited $100 \mathrm{~nm}$ silicon dioxide, which meant that the super-hydrophilic deposition layer did not change the surface topography significantly.

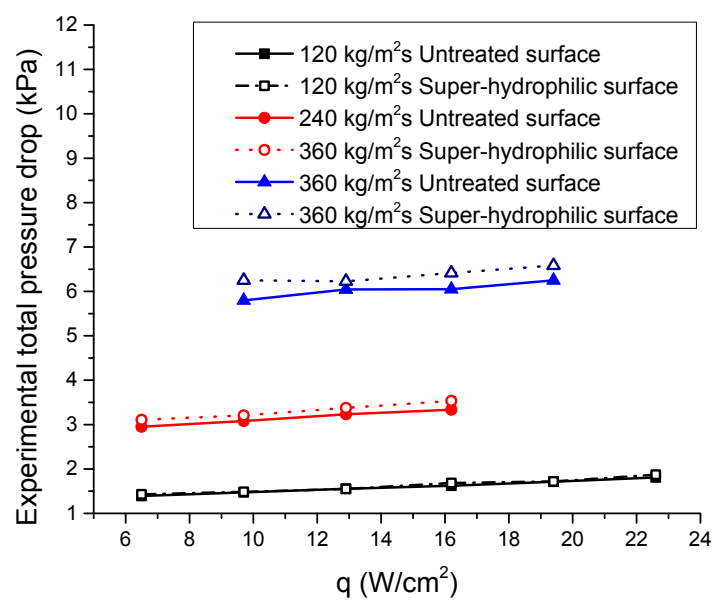

\section{CONCLUSIONS}

In the present study the pressure drop, local heat transfer coefficient and flow pattern of saturated flow boiling in a single-sided-heated microchannel of different surface wettability were measured and visualized using deionized water as the working fluid. The bare silicon wafer surface was hydrophilic with a contact angle of $65^{\circ} \pm 3^{\circ}$, compared with super-hydrophilic surface deposited by a thin film of $100 \mathrm{~nm}$-thickness silicon dioxide through PECVD with a contact angle less than $5^{\circ}$. During the experiments, the mass fluxes were in the range of $120 \mathrm{~kg} / \mathrm{m}^{2} \mathrm{~s}-360 \mathrm{~kg} / \mathrm{m}^{2} \mathrm{~s}$, the wall heat fluxes were spanned from $4 \mathrm{~W} / \mathrm{cm}^{2}$ to $20 \mathrm{~W} / \mathrm{cm}^{2}$ and the inlet vapor qualities were varied from 0.03 to 0.1 . The main conclusions were summarized as follows:

(1) The local heat transfer coefficients in the annular flow regime first decreased along the test section and then increased towards the exit, thus displaying minima roughly half-way through the test section. These minima are likely due to the trade-off between a developing 
thermal boundary layer within the liquid film and the thinning of the film itself due to evaporation.

(2) According to flow visualization, the local dryout phenomenon occurred on the untreated hydrophilic surface at high heat fluxes for low mass fluxes, coupled with deteriorated heat transfer performance, while it was not observed on the super-hydrophilic surface at identical conditions. Meanwhile severe heat transfer deterioration was obtained on the hydrophilic surface with increased inlet vapor quality, while the heat transfer coefficient of the superhydrophilic surface was nearly constant at the same test condition, which outperformed the untreated silicon wafer surface without an increased pressure drop penalty.

\section{ACKNOWLEDGEMENTS}

This work is supported by MISTI Greater China Fund for Innovation, the National Science Foundation of China (51210011), National Science Foundation of Zhejiang Province (LZ13E060001), and Zhejiang Provincial Public Projects (analysis and test) of Zhejiang Province (2015C37027), China. The authors appreciate Dr. Zhaozan Feng at CRRC in Zhuzhou Institute Company, Dr. Thomas J McKrell in Mechanical Engineering at MIT, and Dr. Zan Wu in Energy Engineering at Lund University for helping in the experimental setup. The authors thank Dr. Shushen Lv in Chemical Engineering at Sun Yat-Sen University for providing the graphite sheet.

\section{REFERENCES}

1. B. Sundén, Introduction to Heat Transfer, WIT Press, Southampton, 2012.

2. S. S. Bertsch, E. A. Groll, S. V. Garimella, Effects of heat flux, mass flux, vapor quality, and saturation temperature on flow boiling heat transfer in microchannels, International Journal of Multiphase Flow, 2009, 35(2):142-154.

3. G. Ribatski, H. A. Navarro, L. Cabezas-Gómez, J. M. Saíz-Jabardo, The advantages of evaporation in micro-scale channels to cool microelectronic devices, Thermal Engineering, 2007, 6(2): 34-39.

4. W. Qu, I. Mudawar, Flow boiling heat transfer in two-phase micro-channel heat sinks-I. Experimental investigation and assessment of correlation methods, International Journal of Heat \& Mass Transfer, 2003, 46(15):2755-2771.

5. M. Piasecka, M. E. Poniewski, Hysteresis phenomena at the onset of subcooled nucleate flow boiling in microchannels, Heat transfer engineering, 2004, 25(3): 44-51.

6. W. Qu, I. Mudawar, Experimental and numerical study of pressure drop and heat transfer in a single-phase micro-channel heat sink, International Journal of Heat \& Mass Transfer, 2002, 45(12):2549-2565.

7. L. Cheng, G. Xia, Fundamental issues, mechanisms and models of flow boiling heat transfer in microscale channels, International Journal of Heat \& Mass Transfer, 2017, 108:97-127.

8. Y. Li, G. Xia, Y. Jia, Y. Cheng, J. Wang, Experimental investigation of flow boiling performance in microchannels with and without triangular cavities - A comparative study, International Journal of Heat and Mass Transfer, 2017, 108: 1511-1526.

9. S. G. Kandlikar, History, advances, and challenges in liquid flow and flow boiling heat transfer in microchannels: a critical review, Journal of Heat Transfer, 2010, 134(3):255-277.

10. W. $\mathrm{Li}, \mathrm{Z}$. Wu, A general criterion for evaporative heat transfer in micro/mini-channels, International Journal of Heat and Mass Transfer, 2010, 53(9-10): 1967-1976.

11. W. Li, Z. Wu, A general correlation for evaporative heat transfer in micro/mini-channels, International Journal of Heat and Mass Transfer, 2010, 53(9-10): 1778-1787.

12. C.L. Ong, J.R. Thome, Macro-to-microchannel transition in two-phase flow: Part 1-Two-phase flow patterns and film thickness measurements, Experimental Thermal and Fluid Science, 2011, 35(1): 37-47.

13. C.L. Ong, J.R. Thome, Macro-to-microchannel transition in two-phase flow: Part 2-Flow boiling heat transfer and critical heat flux, Experimental thermal and fluid science, 2011, 35(6): 873-886.

14. H. O’Hanley, C. Coyle, J. Buongiorno, T. McKrell, L. W. Hu, M. Rubner, R. Cohen, Separate effects of surface roughness, wettability, and porosity on the boiling critical heat flux, Applied Physics Letters, 2013, 103(2): 024102.

15. M. Tetreault-Friend, R. Azizian, M. Bucci, T. McKrell, J. Buongiorno, M. Rubner, R. Cohen, Critical heat flux maxima resulting from the controlled morphology of nanoporous hydrophilic surface layers, Applied Physics Letters, 2016, 108(24): 243102.

16. N. S. Dhillon, J. Buongiorno, K. K. Varanasi, Critical heat flux maxima during boiling crisis on textured surfaces, Nature communications, 2015, 6 .

17. A. S. Kousalya, K. P. Singh, T. S. Fisher, Heterogeneous wetting surfaces with graphitic petaldecorated carbon nanotubes for enhanced flow boiling, International Journal of Heat \& Mass Transfer, 2015, 87:380-389. 
18. C. Li, G.P. Peterson, Parametric study of pool boiling on horizontal highly conductive microporous coated surfaces, ASME J. Heat Transfer, 2007, 129(11): 1465-1475.

19. S. J. Penley, R. A. Wirtz, Correlation of subatmospheric pressure, saturated, pool boiling of water on a structured-porous surface, Journal of Heat Transfer, 2011, 133(4):649-659.

20. B. M. Mognetti, J. M. Yeomans, Capillary filling in microchannels patterned by posts, Physical Review E, 2009, 80(5): 056309.

21. R. Furberg, B. Palm, S. Li, M. Toprak, M. Muhammed, The use of a nano-and microporous surface layer to enhance boiling in a plate heat exchanger, Journal of heat transfer, 2009, 131(10): 101010 .

22. R. Rioboo, M. Marengo, S. Dall'Olio, M. Voué, J. De Coninck, An innovative method to control the incipient flow boiling through grafted surfaces with chemical patterns, Langmuir, 2009, 25(11): 6005-6009.

23. C. Choi, J. S. Shin, D. I. Yu, M. H. Kim, Flow boiling behaviors in hydrophilic and hydrophobic microchannels, Experimental Thermal and Fluid Science, 2011, 35(5): 816-824.

24. T. Y. Liu, P. L. Li, C. W. Liu, C. Gau, Boiling flow characteristics in microchannels with very hydrophobic surface to super-hydrophilic surface, International Journal of Heat and Mass Transfer, 2011, 54(1): 126-134.

25. S. S. Hsieh, C. Y. Lin, Subcooled convective boiling in structured surface microchannels, Journal of Micromechanics and Microengineering, 2009, 20(1): 015027.

26. S. S. Hsieh, C. Y. Lin, Correlation of critical heat flux and two-phase friction factor for subcooled convective boiling in structured surface microchannels, International Journal of Heat and Mass Transfer, 2012, 55(1): 32-42.

27. R. Ahmadi, T. Okawa, Influence of surface wettability on bubble behavior and void evolution in subcooled flow boiling, International Journal of Thermal Sciences, 2015, 97: 114-125.

28. S. C. Cho, Y. Wang, Two-phase flow dynamics in a micro channel with heterogeneous surfaces, International Journal of Heat and Mass Transfer, 2014, 71: 349-360.

29. F. M. White, Fluid mechanics. 5th , Boston: McGraw-Hill Book Company, 2003.

30. S. Kandlikar, S. Garimella, D. Li, S. Colin, M. R. King, Heat transfer and fluid flow in minichannels and microchannels, elsevier, 2005.

31. S. Z. Rouhani, E. Axelsson, Calculation of void volume fraction in the subcooled and quality boiling regions, International Journal of Heat and Mass Transfer, 1970, 13(2): 383-393.

32. R. J. Moffat, Describing the uncertainties in experimental results, Experimental Thermal \& Fluid Science, 1988, 1(1): 3-17.

33. T. Hibiki, K. Mishima, Flow regime transition criteria for upward two-phase flow in vertical narrow rectangular channels, Nuclear Engineering and Design, 2001, 203(2): 117-131.

34. J. L. Xu, P. Cheng, T. S. Zhao, Gas-liquid two-phase flow regimes in rectangular channels with mini/micro channels, International Journal of Multiphase Flow, 1999, 25(3): 411-432.

35. Y. Taitel, D. Bornea, A. E. Dukler, Modelling flow pattern transitions for steady upward gasliquid flow in vertical tubes, AIChE Journal, 1980, 26(3): 345-354.

36. A. Ullmann, N. Brauner, The prediction of flow pattern maps in minichannels, Multiphase Science and Technology, 2007, 19(1).

37. H. Ohta, K. Inoue, M. Ando, K. Watanabe, Experimental investigation on observed scattering in heat transfer characteristics for flow boiling in a small diameter tube, Heat transfer engineering, 2009, 30(1-2): 19-27.

38. T. G. Karayiannis, M. M. Mahmoud, D. B. R. Kenning, A study of discrepancies in flow boiling results in small to microdiameter metallic tubes, Experimental thermal and fluid science, 2012, 36: $126-142$.

39. E. Costa-Patry, J. Olivier, B. Michel, J. R. Thome, Two-phase flow of refrigerants in $85 \mu \mathrm{m}$-wide multi-microchannels: Part II-Heat transfer with 35 local heaters, International Journal of Heat and Fluid Flow, 2011, 32(2): 464-476. 